\title{
A Cooperação Como Categoria Ideológica na Formação do Licenciado em Educação Física na Condução de Atitudes Agressivas no Ensino Fundamental The Cooperation as an Ideological Category in the Training of Physical Education Licensed Pro- fessional for the Management of Aggressive Driving Attitudes in Elementary School
}

\author{
Paloma Cathilyne Justen', Alvori Ahlert ${ }^{2}$
}

\author{
${ }^{1}$ Licenciada em Educação Física pela Universidade Estadual do Oeste do Paraná - UNIOESTE. - palomajusten@ \\ hotmail.com \\ 2 Pós-Doutor em Educação, Doutor em Teologia (Área: Religião e Educação), Mestre em Educação nas Ciências \\ (Área Filosofia). Professor Associado da Universidade Estadual do Oeste do Paraná-UNIOESTE.
}

Recebido em 08 de fevereiro de 2018; Aceito em 08 de junho de 2018.

\section{Resumo}

O estudo teve como tema a cooperação e as atitudes agressivas. O objetivo geral do estudo foi verificar se durante as aulas de educação física, sustentada na ideologia cooperativa, existem atitudes agressivas, em escolas públicas municipais de Marechal Cândido Rondon - PR. A pesquisa foi descritiva e os sujeitos do estudo foram aulas de Educação Física com alunos e alunas do 4ㅇ e 5ㅇ anos do Ensino Fundamental. A metodologia foi um estudo de caso realizado através da observação direta durante as aulas e entrevista semiestruturada com a docente das turmas observadas. Os resultados encontrados, a partir das observações, confirmaram a diminuição significativa das atitudes agressivas durante as aulas de Educação Física a partir do trabalho da cooperação como atitude permanente durante as aulas. Concluiu-se que a ideologia da cooperação como instrumento didático-pedagógico permanente, diminui as atitudes agressivas durante as aulas de educação física.

Palavras-Chave:Ideologia. Cooperação. Licenciado em Educação Física. Formação profissional.

\begin{abstract}
The study theme was cooperation and aggressive attitudes. The overall objective of the study was to determines whether during physical education classes, held in the cooperative ideology, there are aggressive attitudes in public schools in Marechal Cândido Rondon - PR. The research was descriptive and the study subjects were Physical Education classes with boys and girls of 4 th and 5 th grades at elementary school. The methodology was a case study through direct observation during semi structured and interview classes. The results from the observations and interview, confirmed the significant decrease in aggressive attitudes during physical education classes from the cooperation work as a permanent attitude in class. It was concluded that the ideology of cooperation as a permanent didactic and pedagogical tool, decreases aggressive attitudes during physical education classes.
\end{abstract}

Keywords: Ideology. Cooperation. Degree in Physical Education. Professional qualification. 


\section{INTRODUÇÃO}

Discutir a formação e o trabalho docente implica saber que o professor e a professora têm sua história de vida, seus anseios e necessidades, seus desejos e utopias, suas angústias e preocupações. Significa que essa história constitui uma visão de mundo com a qual o novo profissional adentra o mundo do trabalho em educação.

E o campo de atuação desse profissional traz como principal característica na atualidade a exacerbada individualização fomentada pelo pensamento neoliberal, que visa "empoderar" cada indivíduo para a competitividade individual e na desconstrução do outro e do coletivo. Por isso, a realidade escolar está marcada pelo crescimento da agressividade em todos os setores.

Isso evidencia a necessidade de revisitarmos, de estudarmos permanentemente as dimensões de ideologia e a formação docente no processo educativo. As licenciaturas precisam ter clareza sobre a relevância de seus projetos de trabalho e a coerência dos mesmos com o que se denomina de função social da universidade, questionando-se sobre a ideologia que sustenta este profissional, sobre o que vai referenciar a qualidade de trabalho desse profissional: o "mercado"? É o melhor indicador?

Marilena Chauí define ideologia como,

[...] um conjunto lógico, sistemático e coerente de representações (ideias e valores) e de normas ou regras (de conduta) que indicam e prescrevem aos membros de uma sociedade o que devem pensar e como devem pensar, o que devem valorizar e como devem valorizar, o que devem sentir e como devem sentir, o que devem fazer e como devem fazer" (CHAUÍ, 2013, p. 117).

E, Paulo Freire, em sua obra síntese, Pedagogia da Autonomia, lembra que a educação não é neutra.

Saber igualmente fundamental à prática educativa do professor ou da professora é o que diz respeito à força, às vezes maior do que pensamos, da ideologia. E o que nos adverte de suas manhas, das armadilhas em que nos faz cair. É que a ideologia tem que ver diretamente com a ocultação da verdade dos fatos, com o uso da linguagem para penumbrar ou opacizar a realidade ao mesmo tempo em que nos torna "míopes". (FREIRE, 1996, p. 125)

No contexto da Educação Física, Jorge S. P. Gallardo defende uma formação hominizada. "A hominização é um processo de complexificação irreversível, cuja originalidade está na capacidade do ser humano em agir e nessa ação poder transformar o meio" (GALLARDO, 2009, p. 87).

Essa hominização passa pela dimensão ideológica que desenvolve o

[...] compromisso social com ênfase na concepção histórico-social do trabalho, estimulando análises políticas sobre as lutas históricas pela superação da sociedade de classes, para que seja garantido o acesso aos bens a todos que dele participam em sua produção, especificamente no campo da cultura corporal. (TAFFAREL et. al., 2007, p. 47)

A docência e sua formação têm o desafio da construção de uma profissionalidade com competências para produzir efeitos na escola, na sala de aula, para enfrentar as necessidades do cotidiano numa perspec- 
tiva de relação dialética com os conceitos e com o desenvolvimento das ciências para re-significar as aprendizagens e, assim, manter acesa a utopia por um mundo mais justo, humano e fraterno. Conforme Marques (1995, p. 123), "É a paixão pelo homem que faz o educador. Apesar das desigualdades e angústias, o autêntico professor acredita no homem que está no aluno e busca conferir-lhe o imenso privilégio de acreditar em si".

A Educação Física escolar vem sofrendo importantes mudanças e transformações. Uma dessas mudanças é o crescimento da consciência ideológica numa perspectiva de coletividade e cooperação entre os seres humanos, o que levou à implantação dos jogos cooperativos dentro das escolas. Conforme Soler (2005), os jogos cooperativos podem ser entendidos como um processo educativo que é baseado na resolução pacífica dos conflitos e também na cooperação, com o propósito de unir as pessoas ao redor de um mesmo objetivo.

Segundo Brotto (2002), foi a partir da preocupação com a excessiva valorização ao individualismo e a competição exacerbada que surgiram os jogos cooperativos, de forma que a partir deles os indivíduos joguem uns com os outros e não uns contra os outros. Amaral (2004) explica que os jogos cooperativos têm como proposta principal a busca de novas formas para jogar, com o intuito de diminuir as manifestações de agressividade durante os jogos.

Podemos considerar que a competitividade dentro do jogo pode ser de grande influência para as manifestações de atitudes agressivas das crianças. Pensando dessa forma, podemos levar em consideração que a partir da aplicação dos jogos cooperativos durante as aulas de Educação Física, uma das expectativas é a diminuição ou extinção das atitudes agressivas dos alunos.

Segundo Brandl Neto (2012), a Associação dos Municípios do Oeste do Paraná (AMOP) implantou no ano de 2007 o Currículo Básico para a Escola Pública Municipal, e no ano de 2010 foi realizada uma revisão das diretrizes da Educação Física. E a partir desse ano a cooperação foi considerada como atitude permanente que transpassa todos os conteúdos e ações da aula. Em Marechal Cândido Rondon, no início de 2011, os docentes das escolas públicas municipais tiveram conhecimento dessa orientação e colocaram em ação em suas aulas (BRANDL NETO, 2012).

Um dos aspectos apontados por Orlick (1989), Brotto (2002) e Amaral (2004), diz respeito à cooperação como forma de amenizar atitudes violentas. Por isso a cooperação tem valor inestimável para as aulas de Educação Física, pois, a partir da mesma, espera-se a diminuição da agressividade, promovendo atitudes de sensibilidade, cooperação, amizade, união, além de que buscam a interação de todos (BROTTO, 2002; AMARAL, 2004; SOLER, 2005).

Portanto, esta pesquisa teve como objetivo investigar atitudes agressivas entre discentes de $4^{\circ}$ e $5^{\circ}$ ano do Ensino Fundamental durante as aulas de Educação Física com orientações cooperativas, em escolas da rede pública municipal de Marechal Cândido Rondon - PR. Buscamos compreender os conceitos de cooperação e agressividade, e o uso da cooperação como atitude permanente durante as aulas de Educação Física. Realizamos observações para identificar a ocorrência de atitudes agressivas e as formas mais frequentes, e a análise e discussão a partir de avaliações com a professora de classe sobre a relação entre a cooperação como atitude permanente para canalizar as atitudes agressivas dos escolares nas aulas de Educação Física.

\section{REVISÃO DE LITERATURA - A COOPERAÇÃO COMO CATEGORIA IDEOLÓGICA NA PRÁTICA DOCENTE}

Segundo Ferreira (apud BRANDL NETO, 2002) o termo cooperação vem do latim cooperatione e significa ato ou efeito de cooperar. Brotto $(2002$, p.27) define cooperação "como a ação que se realiza em con- 
junção com outra pessoa ou pessoas para conseguirem o mesmo fim". Sendo assim, podemos considerar cooperação quando duas ou mais pessoas se unem, para juntas conseguirem chegar ao mesmo objetivo.

Hartmann, citado por Orlick (1989), afirma: “A cooperação é a força unificadora mais positiva, que agrupa uma variedade de indivíduos com interesses separados numa unidade coletiva." Isso significa que a cooperação se constitui numa ideologia com poder de unir pessoas com os mais diversos interesses. Por isso Correia (2006) propõe a cooperação no ambiente escolar principalmente nas aulas de Educação Física para trabalhar diversos valores com os alunos, como por exemplo a solidariedade, a liberdade e a cooperação.

Para Inácio Brandl Neto,

A cooperação, além disso, dá suporte e apoio para que os conflitos se resolvam. Cooperando acontecem não só melhores perguntas, como também melhores respostas. Os alunos se ajudam, se corrigem mutualmente, controem novos argumentos e ideais que, de modo separado, dificilmente ocorreriam (2002, p. 52).

Amaral (apud BRANDL; BRANDL NETO, 2013) acredita que quando as pessoas se desenvolvem em meio à cooperação, elas passam a gostar, partilhar e se relacionar com os outros com mais solidariedade, pois entende que cada pessoa tem um papel importante para desempenhar. Os mesmos autores afirmam que esses valores cooperativos propõem a diminuição da agressividade, pois é através desses valores que acontecem a promoção de atitudes positivas como cooperação, amizade, alegria, etc. Da mesma forma Soler (apud BRANDL; BRANDL NETO, 2013) afirma que ao se falar em cooperação, estamos falando também em aceitação, ajuda mútua, qualidade de vida.

Podemos perceber que através da cooperação, além de acontecer a ajuda mútua para chegar ao mesmo objetivo, ou ajudar o próximo, contribuímos também na construção do nosso próprio eu.

A cooperação contínua é talvez mais importante para o homem que para qualquer outra espécie, porque a ação humana tem um efeito direto sobre todas as outras espécies. Não só tem a capacidade de enriquecer ou destruir a si mesmo, como também a todo o ambiente natural (ORLICK, 1989, p.22)

Por isso as atitudes cooperativas podem tornar-se uma importante dimensão ideológica para toda a sociedade e não somente dentro das escolas. A partir disso, também entendemos tamanha importância de trabalhar a cooperação como atitude permanente dentro das escolas desde os primeiros anos, até os anos finais, pois será a partir desse trabalho que conseguiremos diminuir cada vez mais a competitividade desnecessária no mundo.

\section{ATIVIDADES E JOGOS COOPERATIVOS}

Amaral (2004) define os jogos cooperativos como atividades que recrutam um trabalho em equipe com o objetivo de alcançar metas mutuamente aceitáveis. O mesmo autor relata que os jogos cooperativos buscam canalizar qualidades ou habilidades de cada indivíduo, e aplicá-las em um grupo, onde assim com todos trabalhando cooperativamente, cada um com sua individualidade, conseguirão alcançar um objetivo comum.

Jogos cooperativos são dinâmicas de grupo que têm por objetivo, em primeiro lugar, despertar a consciência de cooperação, isto é, mostrar 
que a cooperação é uma alternativa possível e saudável no campo das relações sociais; em segundo lugar, promove efetivamente a cooperação entre as pessoas, na exata medida em que os jogos são eles próprios, experiências cooperativas (BARRETO apud SOLER, 2009, p. 56).

Soler (2009, p. 44) afirma que "jogar cooperativamente é deixar aflorar a beleza do jogo é imaginar fazer parte de um grande e único time, onde o esforço mútuo serve para nos impulsionar cada vez mais longe". Dessa forma podemos entender que nos jogos cooperativos o mais importante é a colaboração de cada indivíduo para com o grupo.

Soler (apud BRANDL; BRANDL NETO, 2013) aponta quatro princípios que são fundamentais dos jogos cooperativos, são eles: inclusão, coletividade, igualdade de direitos e deveres e desenvolvimento humano. Entendemos assim que os jogos cooperativos refletem positivamente na construção do indivíduo, sendo de suma importância o trabalho do mesmo nas escolas.

Com relação à agressividade, Amaral (2004, p.14) afirma que "os jogos cooperativos propõem a busca de novas formas de jogar, com o intuito de diminuir as manifestações de agressividade nos jogos, promovendo atitudes de sensibilidade, cooperação, comunicação, alegria e solidariedade." Dessa forma as manifestações agressivas serão diminuídas devido à exclusão da competição das aulas, assim o aluno joga por prazer e pelo divertimento, e não pelo simples fato de vencer.

Por isso acredita-se que o jogo cooperativo é de grande importância para Educação Física, pois além de desenvolver as habilidades motoras através dos jogos, acontece também o desenvolvimento de valores, atitudes corretas, os mais diversos aprendizados que enriquecem as crianças.

A seguir apresentamos um quadro onde é possível entender de forma clara a diferença entre os jogos competitivos e os jogos cooperativos:

Quadro 01: Diferença entre jogos competitivos e cooperativos.

\begin{tabular}{|c|c|}
\hline JOGOS COMPETITIVOS & JOGOS COOPERATIVOS \\
\hline São divertidos apenas para alguns & São divertidos para todos \\
\hline A maioria tem um sentimento de derrota & Todos tem um sentimento de vitória \\
\hline Alguns são excluídos por sua falta de habilidade & $\begin{array}{c}\text { Há mistura de grupos que brincam juntos criando } \\
\text { alto nível de aceitação mútua. }\end{array}$ \\
\hline Aprende-se a ser desconfiado & Todos participam e ninguém é rejeitado ou \\
\hline Os perdedores ficam de fora do jogo e se tornam \\
observadores & Os jogadores aprendem a ter um senso de \\
unidade e a compartilhar o sucesso
\end{tabular}

Fonte: Brotto (2003) 
Por meio dessa Tabela podemos perceber o quanto os jogos cooperativos se sobressaem ao jogo competitivo. Os jogos cooperativos auxiliam os jogadores a aprenderem a solucionar os problemas e conflitos, através da participação de todos.

\title{
AS ATITUDES AGRESSIVAS EM ESCOLARES DO ENSINO FUNDAMENTAL
}

Antes de falarmos sobre as atitudes agressivas em crianças, é importante primeiramente, entender de forma clara o que são as atitudes.

\begin{abstract}
A partir da percepção do meio social e dos outros, o indivíduo vai organizando estas informações, relacionando-as com afetos (positivos ou negativos) e desenvolvendo uma predisposição para agir (favorável ou desfavoravelmente) em relação às pessoas e aos objetos presentes no meio social. A essas informações com forte carga afetiva, que predispõe o indivíduo para uma determinada ação (comportamento), damos o nome de atitudes (BOCK; FURTADO; TEIXEIRA, 1995, p. 127).
\end{abstract}

Portanto, cada indivíduo tem o poder de modificar suas atitudes a partir de novas informações. São as nossas atitudes que irão determinar como cada indivíduo ira se relacionar com o meio. Outro fator determinante também da atitude é a situação em que o indivíduo se encontra, ou seja, em situação normal o indivíduo se comportaria de determinada maneira, mas devido ao fato de haver alguma situação especial, ele tem uma atitude diferente do esperado.

Conforme Sarabia (apud BRANDL NETO, 2002), a formação e mudança da atitude de cada indivíduo operam em três componentes básicos: o cognitivo, o afetivo e o de conduta.

É através das atitudes que o indivíduo evidência seu grau de agressividade nas diferentes situações nas quais elas se confrontam como o inusitado, o repetitivo, o diferente, o contraditório. Consequentemente, estudar as atitudes agressivas em escolares demanda compreender melhor o significado da agressividade nessa fase da vida.

Existem várias definições para agressividade. Segundo Bandura (apud SOARES, 2004), a agressividade pode ser como um comportamento que resulta em uma injúria pessoal ou destruição de algo, evidenciando assim não a intenção que o agressor teve, mas sim a sua ação. Bock et al. (1995) definem a agressividade como um impulso destrutivo. Esse impulso pode ser intencional e premeditado ou involuntário.

Erich Fromm (1979) distingue as formas de agressividade. Para ele a agressividade intencional é definida como maligna, enquanto que a involuntária é compreendida como agressividade benigna. Explica que a agressão benigna é defensiva, ou seja, é instintiva, biologicamente adaptativa, pois quando o indivíduo percebe que a ameaça cessou, automaticamente a atitude agressiva também acaba. Esse tipo de agressão faz parte na natureza humana. Entretanto, a agressividade maligna existe somente na espécie humana e não serve para sua sobrevivência. Esse tipo de agressividade visa a destrutividade e a crueldade.

Desta forma podemos perceber que a agressividade de cada indivíduo depende muito dos dois fatores, o biológico e o social, e eles estão interligados. Quando abordamos os fatores sociais ligados às atitudes agressivas, a primeira coisa que pensamos é em relação ao contexto familiar, mas vai muito além disso. Em um estudo, Lippelt (2004) cita alguns fatores, além do contexto familiar, que contribuem para o aumento das atitudes agressivas, são eles: mídia, atitudes negativas do professor, drogas, depredação e indisciplina. 
Relacionado aos tipos de agressividade, existem diferentes classificações. Helen Bee (1996) classificou a agressividade em duas formas. A agressão instrumental, que acontece quando o indivíduo busca uma recompensa e não o sofrimento de outra pessoa. A outra forma de agressão é a hostil, onde a principal intenção do indivíduo é atacar outra pessoa.

Além da classificação em agressividade hostil e instrumental, podemos classificar os mecanismos utilizados para a agressão. Corsini (apud SOARES et al. 2004) separa a agressividade em agressão verbal (quando o indivíduo se utiliza de palavras ou expressões verbais) e agressão física (quando o indivíduo realiza um ataque físico a outro). Costa Vale (apud SOUSA, 2005) fala sobre um terceiro tipo de agressão, que é denominada de agressão social. Ela pode ser caracterizada pela exclusão da criança, por ser alvo de rumores desagradáveis ou até mesmo por ninguém conversar com a criança.

A agressividade deve ser respeitada e trabalhada de forma construtiva e consciente do indivíduo; do contrário, torna-se nociva, deturpando os valores individuais e sociais, bloqueando a relação com o outro. Isso vai influenciar a personalidade do indivíduo, tornando-o mais ou menos agressivo e trazendo-lhe, assim, efeitos negativos (DIAS, 1996). Assim, entendemos que o comportamento agressivo pode ser modificado, dependendo da forma com que o intermediador trabalha, para melhor ou pior.

É importante também sabermos como agir perante as atitudes agressivas, e primeiramente devemos deixar claro que cada acontecimento conflitante diferente, exige uma intervenção diferente, essas intervenções devem apontar para três objetivos básicos: prevenção, intervenção e solução de conflito (FERNANDEZ, 2005).

\section{METODOLOGIA}

Nosso estudo caracterizou-se como pesquisa descritiva que, conforme Gil (1999, p. 44) “[...] tem como objetivo primordial a descrição das características de determinada população ou fenômeno ou o estabelecimento de relações entre variáveis". A abordagem escolhida para verificar as situações da pesquisa foi o modo qualitativo como a coleta das informações direta do ambiente natural e o pesquisador como instrumento principal. Nesse caso, o processo implicou em estudos na literatura, observações, entrevista e análises de informações que foram elaboradas de forma descritiva, dando ênfase no processo, e não no resultado final. (ANDRÉ, 2004; OLIVEIRA, 2008). Para esses autores a descrição é a maneira mais eficaz de obter informações no cotidiano escolar.

Os sujeitos da Pesquisa foram alunos e alunas do Ensino fundamental do 4o e 5o ano do município de Marechal Cândido Rondon. A escolha da escola e turmas foi feita por acessibilidade. "O pesquisador seleciona os elementos a que tem acesso, admitindo que possam de alguma forma, representar o universo" (GIL, 1999, p.104). Para o desenvolvimento do estudo foram utilizados como instrumentos para coleta de dados observações nas turmas selecionadas e entrevista semi-estruturada com a professora de turma.

\section{ANÁLISE E DISCUSSÃO DOS DADOS}

Através das observações procurou-se analisar se mesmo com a docente adotando as atitudes cooperativas como atitude permanente nas suas aulas, ainda existiam atitudes agressivas, qual o tipo e o mecanismo utilizado para a atitude agressiva.

A turma " $A$ " era composta por 18 alunos, dos quais 10 são meninos e oito são meninas. Durante as observações o conteúdo trabalhado pela docente foram jogos e brincadeiras e jogos pré-desportivos do voleibol. As aulas aconteceram em quadra que não era coberta e no saguão da Escola. As atividades realizadas 
durante esse período foram cooperativas ou semi-cooperativas, mas a docente trabalhou constantemente com a cooperação como atitude permanente. Durante minhas observações notei que a turma é participativa. Eles têm um bom entrosamento entre eles e com a docente.

A partir das observações das aulas, e a descrição da mesma, foi percebido que não houve nenhuma forma de agressão hostil, que é quando o indivíduo realiza o ato com a intenção de ferir algo/alguém. Em relação às atitudes agressivas observadas durante as aulas, do tipo instrumental. Seguem os dados:

Quadro 02:Quantidade de atitudes agressivas (instrumental) observadas durante as aulas da turma " $A$ ".

\begin{tabular}{|c|c|c|c|c|c|}
\hline & AULA 01 & AULA 02 & AULA 03 & AULA 04 & AULA 05 \\
\hline VERBAL & & & & & \\
\hline FÍSICA & & 1 & & & \\
\hline SOCIAL & & & & & \\
\hline
\end{tabular}

Fonte: os autores

A partir do Quadro 2 podemos constatar que nas cinco observações realizadas nessa turma aconteceu na aula dois apenas uma atitude agressiva de um colega para com o outro. O mecanismo utilizado foi a agressão física.

Um trecho da descrição da observação relata como aconteceu a atitude agressiva:

'[...] um discente do sexo masculino empurrou seu colega (não muito forte) durante a execução de uma atividade, para alertá-lo que estava na sua vez de jogar. A docente percebendo a atitude, imediatamente parou sua aula, e perguntou para o agressor se ele teve a atitude correta. o discente após responder que não, pediu desculpas para seu colega, sem a professora precisar pedir para fazer isso [...]'. Através disso percebemos que a intenção do aluno não foi empurrar para machucar seu colega, e sim chamar a atenção dele através do empurrão.

Nos outros dias de observações não ocorreram atitudes agressivas entre eles. Pelo que se pode perceber nas aulas, o trabalho da docente com a turma a respeito da cooperação como atitude permanente é contínuo e eficaz. Ao final de cada atividade e aula, ela reunia a turma e conversava sobre a mesma, interligando os fatos que aconteceram a valores e aprendizados.

Ao final da aula na qual ocorreu a agressão física, a docente reuniu a turma para conversar, assim como nas outras aulas. A docente com relação ao caso apenas fez os alunos pensarem na melhor solução para evitar tais atitudes.

Atitude docente ao final da aula: a docente, como de costume, reuniu os alunos para a conversa final. Todos se sentaram em círculo e a conversa foi sobre a atitude agressiva aconteceu na aula. Ela questionou todos os alunos sobre a atitude e, através da conversa, fez todos pensarem na atitude correta a ser toma- 
da nessas situações. Ela também levou essa situação para fora da escola, citando exemplos para os alunos entenderem que não devem ter o comportamento correto somente na escola, e sim na sua vida. Segundo Brandl e Brandl Neto (2013), a cooperação contribui nas propostas dentro e fora da escola.

Pode-se perceber que a docente realiza um trabalho contínuo relacionado à cooperação com a turma. Em todas as conversas que observei os alunos interagiram com a docente, respondendo os questionamentos, relatando fatos relacionados ao assunto, tirando dúvidas.

A turma "B" era composta por 17 alunos, dentre os quais nove eram meninas e oito meninos. Os conteúdos trabalhados durante as aulas de observação foram jogos pré-desportivos do voleibol, jogos e brincadeiras e jogos de mesa. As aulas aconteceram em quadra e no saguão da Escola. As atividades realizadas foram cooperativas e semi-cooperativas. Durante as observações todos os alunos participaram. Somente na aula número quatro uma aluna ficou sem participar da aula, pois estava com o joelho machucado. A turma se mostrou bem participativa e com um bom entrosamento.

Na aula número um houve a ocorrência de uma atitude agressiva hostil, que para Bee (1996) é a forma de agressão onde um ou mais indivíduos visam atacar o outro. Seguem abaixo os dados:

Quadro 03:Quantidade de atitudes agressivas (hostil) observadas durante as aulas da turma "B".

\begin{tabular}{|c|c|c|c|c|c|}
\hline & AULA 01 & AULA 02 & AULA 03 & AULA 04 & AULA 05 \\
\hline VERBAL & & & & & \\
\hline FÍSICA & & & & & \\
\hline SOCIAL & 1 & & & & \\
\hline
\end{tabular}

Fonte: os autores

Na primeira aula observada dessa turma, na qual as atividades foram jogos pré-desportivos de voleibol, houve uma agressão hostil social de um grupo de 3 alunos com um outro. "[...] durante o jogo de voleibol rede viva um grupo de três alunos excluíram outro colega devido aos seus trejeitos.[...] " ou seja, o aluno foi deixado de lado pelo grupo devido ao seu jeito. A professora não parou a atividade, só pediu para que os alunos parassem com isso.

Essa atitude agressiva pode ser considerada hostil, pois o grupo de alunos tinha a intenção de "provocar" o outro deixando-o de lado.

Essa atividade foi a última da aula, então quando encerrada a mesma, no momento em que toda a turma estava reunida para conversa final. A docente conversou com a turma sobre a questão do respeito, interligando com o fato que aconteceu na aula. Procurou fazer os alunos pensarem e em um trecho de sua conversa explicou que todos podem passar por isso, que para isso não acontecer todos devem respeitar uns aos outros.

Brandl e Brandl Neto (2013) falam sobre a importância da discussão em grupo após a atividade, pois desta forma o grupo tem possibilidade de estabelecer uma relação entre o que foi feito durante o jogo e a vida. 
Quanto à agressividade instrumental, também constatou-se um episódio na aula de número cinco da turma "B".

Quadro 04: Quantidade de atitudes agressivas (instrumental) observadas durante as aulas da turma "B".

\begin{tabular}{|c|c|c|c|c|c|}
\hline & AULA 01 & AULA 02 & AULA 03 & AULA 04 & AULA 05 \\
\hline VERBAL & & & & & 1 \\
\hline FÍSICA & & & & & \\
\hline SOCIAL & & & & & \\
\hline
\end{tabular}

Fonte: os autores

A seguir, um trecho que descreve como ela ocorreu: "[... ] no decorrer do pegador, como os alunos que eram pegos deveriam abaixar bloqueando a passagem, acabaram restando poucos espaços para os alunos correrem, então um discente que estava atrás do outro o chamou de "lerdo", querendo que dessa forma ele corresse mais rápido para ambos conseguirem fugir. A professora não ouviu, mas logo depois da atitude agressiva o aluno olhou imediatamente para a professora, dando a entender que percebeu que teve uma atitude que não devia".

A atitude agressiva do discente foi com o intuito de seu colega correr mais rápido para melhor desempenho na atividade, ou seja, ele não visava magoar seu colega com a agressão verbal, e sim o fazê-lo perceber que deveria correr um pouco mais rápido.

Além destas duas atitudes agressivas, não ocorreram outras durante as observações realizadas nessa turma. Notamos que o trabalho da professora baseado na cooperação era constante e estava presente em todos os momentos das aulas. Apesar de algumas atividades não terem sido cooperativas ela encontrou um meio para interligá-la com a cooperação.

A turma " $\mathrm{C}$ " era composta por 22 discentes, sendo 10 meninos e 12 meninas. Durante as observações os conteúdos trabalhados foram jogos pré-desportivos de voleibol e jogos e brincadeiras em quadra no saguão e na sala de aula da Escola. As atividades realizadas foram cooperativas e semi-cooperativas, mas o trabalho da docente era constante e relacionado à cooperação. Todos os alunos participaram de todas as aulas. Em uma observação havia apenas 12 discentes. A turma se mostrou bem participativa e unida.

Em relação às atitudes agressivas, dentre todas as aulas observadas nessa turma, não houve nenhuma, nem hostil nem instrumental. Pode-se perceber através de todas as conversas da docente com os discentes, em todos os momentos, que a turma entendeu bem a importância das atitudes cooperativas, pois os alunos se mostraram muito presentes e participativos durante as conversas.

Amaral (2004) cita alguns valores educativos que são conquistados através dos jogos cooperativos: construção de uma relação social positiva, ou seja a mudança de atitudes das pessoas favorecendo um ambiente de apreço; empatia que é a capacidade de compreender o outro, entendendo seu ponto de vista, apreço e auto conceito que é desenvolver uma opinião positiva de si mesmo e também reconhecer a importância dos demais. 
A turma " $D$ " era composta por 17 alunos, com 11 meninos e seis meninas. Durante as observações realizadas nessa turma os conteúdos trabalhados foram jogos pré-desportivos de voleibol e jogos e brincadeiras. As aulas aconteceram em quadra e no saguão da Escola. As atividades podem ser consideradas cooperativas e semi-cooperativas, mas a professora trabalhava continuamente com a cooperação. Todos os alunos participaram das aulas.

Não houve nenhuma atitude agressiva considerada hostil durante a aula. Em relação à agressividade instrumental houve um registro.

Quadro 05:Quantidade de atitudes agressivas (instrumental) observadas durante as aulas da turma "D".

\begin{tabular}{|c|c|c|c|c|c|}
\hline & AULA 01 & AULA 02 & AULA 03 & AULA 04 & AULA 05 \\
\hline VERBAL & & 1 & & & \\
\hline FÍSICA & & & & & \\
\hline SOCIAL & & & & & \\
\hline
\end{tabular}

Fonte: os autores

Por meio do quadro pode-se perceber que ocorreu uma agressão verbal na segunda aula. A agressão partiu do interesse do discente em jogar a bola, que estava com outro aluno. "[...] um discente querendo a bola para jogar pediu para seu colega e o mesmo não passou a bola, então o discente que desejava a bola chamou o outro discente de idiota. No mesmo momento a professora observou a situação e foi conversar com os dois, onde ela explicou que os dois estavam errados, pois o discente que estava com a bola poderia ter jogado junto com o outro aluno, e o discente que teve a atitude agressiva poderia ter tentado conversar com o que estava com a bola, explicando que jogando juntos poderia ser mais divertido. Os alunos concordaram com a professora e se desculparam um com o outro. Logo após a situação os alunos jogaram juntos. [...]".

Através das observações pudemos perceber que as atitudes agressivas durante as aulas podem ser consideradas poucas, sendo que na turma " $C$ " não aconteceu nenhuma atitude agressiva e na turma " $A$ " $\mathrm{e}$ " $D$ " aconteceram apenas uma. Somente na turma "B" aconteceram duas atitudes agressivas, sendo uma hostil e outra instrumental.

Destaca-se que a professora, em todas as aulas, trabalhou com a cooperação de alguma forma, não somente através dos jogos cooperativos, mas através de conversas com os alunos fazendo-os pensar nas mais diversas situações, nas quais eles refletiam sobre a melhor forma de agir diante de determinadas situações. Papalia e Olds (2000) relatam que as experiências em que as crianças passam dentro da escola influenciam muito no seu desenvolvimento. Então, através desse trabalho com as crianças, a docente vai atingindo o objetivo com os discentes. Vale destacar que esse trabalho acontece a longo prazo e é contínuo.

Soler (apud BRANDL; BRANDL NETO 2013) propõe para se trabalhar a cooperação utilizando um ciclo com três elementos. O primeiro elemento é a vivência (ação), o segundo elemento é a reflexão no qual os alunos são instigados a refletir sobre a ação, pensando em modificação com o intuito de melhorar a participação, e o último momento do ciclo é a transformação, em que acontece a ação melhorada. Enquanto observei as aulas da docente, percebi que o mesmo se utilizou desse método. 


\section{CONSIDERAÇÕES FINAIS}

Este estudo teve como objetivo principal investigar se ainda ocorrem atitudes agressivas durante as aulas de Educação Física nas quais se utiliza a dimensão ideológica da cooperação como atitude permanente.

Os resultados encontrados nas observações correlacionadas com a entrevista mostraram que ainda ocorrem atitudes agressivas, porém a diminuição da mesma a partir do trabalho com a cooperação como atitude permanente foi significativa. Também constatamos que a forma mais frequente de agressão é a verbal. A docente através da entrevista confirma o que se esperava, a cooperação é um meio didático poderoso de grande importância para lidar com as atitudes agressivas.

Por isso, a partir deste estudo podemos compreender o valor que a cooperação tem na Educação Física para formação de cidadãos. Por meio de um trabalho organizado e pautado na cooperação é possível reduzir as atitudes agressivas entre escolares nas aulas, e até mesmo dentro da escola e em sua vida.

Nesse sentido, levando em conta que a Educação Física desperta grande interesse na maioria das crianças, torna-se de grande importância um trabalho organizado e pautado na cooperação como meio de lidar com a agressividade. Mas esse compromisso deve ir além das aulas de Educação Física. O comprometimento deve vir da escola como um todo, expandindo esse trabalho inclusive para fora da escola, mediante o envolvimento dos pais e comunidade escolar. A partir disso, o trabalho será mais completo e conseguirá atingir melhores resultados, pois não é somente na escola que acontece a formação de cidadãos.

\section{REFERÊNCIAS BIBLIOGRÁFICAS}

AMARAL, J. D. Jogos cooperativos. São Paulo: Phorte, 2004.

AMOP - Associação dos Municípios do Oeste do Paraná. Currículo básico para a escola pública municipal. Cascavel: Assoeste, 2007.

ANDRÉ, M. D. A., Etnografia da prática escolar. Campinas: Papirus, 2004.

BEE, H. A criança em desenvolvimento. 7. ed. Porto Alegre: Artes Médicas, 1996.

BOCK, A. M. B.; FURTADO, O.; TEIXEIRA, M. I. T. Psicologias:uma introdução ao estudo da psicologia. 8. ed. São Paulo: Editora Saraiva, 1995.

BRANDL, C. E. H; BRANDL NETO, I. Uma proposta pedagógica pautada na cooperação. Curitiba: Editora CRV, 2013.

BRANDL NETO, I. Educação física escolar e o desenvolvimento da atitude cooperativa nos anos iniciais do ensino fundamental. São Paulo, 2012.

BROTTO, F. O. Jogos cooperativos. O jogo e o esporte como um exercício de convivência. Editora Projeto cooperação: Santos, 2001.

. Jogos cooperativos - o jogo e o esporte como um exercício de convivência. 2. Ed. São Paulo: Projeto cooperação, 2002.

Jogos cooperativos. Santos: Projeto cooperação, 2003.

CHAUÍ, M. Manifestações ideológicas do autoritarismo brasileiro. Belo Horizonte: Autêntica, 2013, 294 p.

DIAS, K. P. Educação Física $\mathbf{x}$ violência: uma abordagem com os meninos de rua. Rio de Janeiro: Sprint, 1996. FERNANDEZ, I. Prevenção da violência e solução de conflitos: o clima escolar como fator de qualidade. São 
Paulo: Madras, 2005.

FREIRE, Paulo. Pedagogia da autonomia: saberes necessários à prática educativa. São Paulo: Paz e Terra, 1996.

FROMM, E. Anatomia da destrutividade humana. 2. ed. Rio de Janeiro: Zahar Editores, 1979.

GALLARDO, J. S. P. Educação física: contribuições à formação profissional. Ijuí: Unijuí, 2009.

GIL, A. C. Como Elaborar Projetos de Pesquisa. 2. Ed. São Paulo: Atlas, 1999.

MARQUES, M. O. A aprendizagem na mediação social do aprendido e da docência. ljuí: UNIJUÍ, 1995.

OLIVEIRA, M. M. Como fazer pesquisa qualitativa. Petrópolis: Vozes, 2008.

ORLICK, T. Vencendo a competição. São Paulo: Círculo do Livro, 1989.

PAPALIA, D.E; OLDS, S.W. Desenvolvimento humano. 7. ed. São Paulo: Artmed, 2000.

SOARES, J. G. MENDES, J. V. ANTÃO, S. M. MOURA, R. W. S. SILVA, V. P. Causas atribuídas a agressividade pelos educadores: um estudo na Escola Municipal Brisa Nunes Braz. 2004. Disponível em: http://www.psicopedagogia.com.br/artigos/artigo.asp?entrID=609Acesso em: 15/09/2014.

SOLER, R. Brincando e aprendendo com os jogos cooperativos. 2. Ed. Rio de Janeiro: Sprint, 2005. Brincando e aprendendo com os jogos cooperativos. 2. Ed. Rio de Janeiro: Sprint, 200 Esporte cooperativo: uma proposta para além das quadras e campos e pátios. Rio de Janeiro: Sprint, 2009.

SOUSA, P. M. L. Agressividade em contexto escolar. Disponível em: http://www.psicologia.pt/artigos/textos/ A0261.pdf Acesso em: 15/09/2014.

TAFFAREL, C. Z. et. al. Uma proposição de diretriz curricular para a formação de professores de educação física. In: HILDEBRANT-STRAMANN, R.; TAFFAREL, C. Z. (Org.). Currículo e educação física: formação de professores e prática pedagógica nas escolas. Ijuí: Unijuí, 2007, p. 41-90. 